\title{
Systematic Monitoring and Evaluating the Wear of Alumina Wheel When Grinding the Workpiece of Cr12
}

\author{
Fangyi You $\left(\mathbb{D}\right.$, Wang Zhou $\mathbb{D}$, Xuan Wang $\left(\mathbb{D}\right.$, and Qiulian Dai ${ }^{1}$ \\ College of Mechanical Engineering and Automation, Huaqiao University, Xiamen 361021, China \\ Correspondence should be addressed to Fangyi You; fangyiy@hqu.edu.cn
}

Received 7 December 2020; Revised 28 December 2020; Accepted 6 January 2021; Published 16 January 2021

Academic Editor: Heng Liu

Copyright (c) 2021 Fangyi You et al. This is an open access article distributed under the Creative Commons Attribution License, which permits unrestricted use, distribution, and reproduction in any medium, provided the original work is properly cited.

\begin{abstract}
The performance of the grinding wheel demonstrably affects the machining efficiency and the quality of the workpiece. Therefore, it is essential to evaluate the wear of the wheel and then operate the dressing or replacement in time. The wear procession of the wheel was monitored and evaluated systematically in this paper. A surface grinding experiment was performed by using an alumina wheel to grind the workpiece made of Cr12. The grinding force and the grinding temperature were monitored and measured while the wheel grinds the workpiece. The surface topography of the wheel was also being observed. The distribution of the gray value of pixels in the image of the wheel surface was analyzed by the method of the histogram. Processing of the binary image of the wheel was performed after determining the gray threshold of the gray value. Then, the blockading and the wearing area on the grinding wheel were calculated. Moreover, the relation of the projection area of a single abrasive derived from theory and derived by image recognition was studied. The results of the grinding experiment show that wheel performance degradation occurs when the material removal volume reaches $210 \mathrm{~mm}^{3} / \mathrm{mm}$. At this time, the ratio of blockage area on the grinding wheel reaches $13.4 \%$. The percentage of the wearing area is $9.5 \%$. The method of image recognition combined with grinding temperature is workable to realize monitoring and evaluating the wear of wheels on site without unloading them.
\end{abstract}

\section{Introduction}

Finishing machining of many precision parts that are made of difficult-to-machine material to obtain good surface quality usually needs grinding [1-3]. During the grinding process, the heavily worn wheel has a fatal effect on the workpiece. Many defects of the products are mainly caused due to excessive wear of the grinding wheel in the automatic production line. There is a vital need to perform the dressing operation when the wheel loses its cutting capacity during the grinding process to obtain high precision machining [4-6]. Hence, it is essential to monitor the wear of the wheel online to determine the dressing operation timely. In recent years, many types of research focus on the wear of abrasives and blockage of the wheel during the grinding process. Deutsch and $\mathrm{Wu}$ [7] studied the wear process by using the surface morphology of the grinding wheel and quantified the type and rate of mechanical wear that changes the structure of the grinding wheel through the established model. Tracking the wear process and observing the three stages of wear, fracture accounts for the main kind of wear at the initial period, while attrition wear is the dominant wear mechanism occurring during the second stage, and the whole grain fracture from the wheel occurs in the third stage. The conclusion is consistent with the literature reported by Shi and Malkin [8]. Besides, Ardashev and Dyakonov [9] studied the blockage on the grinding wheel to predict the surface condition of the grinding wheel. A simulation model between abrasive passivation area and grinding force was established and verified by measuring the grinding force.

Wear and bluntness of grinding wheels are inevitable in the grinding process. The grinding force and grinding temperature will vary when the grinding wheel becomes blunt. The surface quality of the workpiece will also decline. Therefore, many researchers take grinding temperature, grinding force, and surface roughness as detection indexes to monitor the wear of the grinding wheel $[10,11]$. Lefebvre et al. [12] studied the 2D finite element model of a wheel on a global scale to predict the temperature of the grinding zone. The simulating results show that the systematic error on the 
maximum temperature rise (MTR) measurement cannot be neglected and is dependent on grinding conditions such as the workpiece velocity and the length of contact arc. Brinksmeier et al. [13] developed a monitoring system with infrared radiation to monitor the grinding zone temperatures. The optical transmission of signal combining with a fast-detecting infrared sensor bares the potential to establish a highly miniaturized measuring system; it is easy to integrate into any grinding wheel. Li et al. [14] established a grinding force model in favor of optimizing the grinding parameters and improving grinding efficiency. Three key factors have been taken into account in this model, such as the contact friction force, the plastic deformation of the material, and the shear strain effect of the material. The values of the grinding force calculated by the model are in good agreement with those of the orthogonal grinding experiment. Thanedar et al. [15] undertook a novel experimental approach for finding practical remedies that are often invoked to avoid grinding burns. After implementation, it is observed that the wheel speed has the most prominent influence in minimizing surface roughness. Azarhoushang et al. [16] put forward another idea to study from the grinding wheel point of view, that is, produced a structural grinding wheel by setting dressing parameters; and its grinding force is reduced by $50 \%$ and the workpiece temperature is reduced by more than $40 \%$.

In the above studies, traditional methods were used to monitor the grinding wheel. However, the method of image processing was used to calibrate the wear area in this paper. Besides, the grinding force, grinding temperature, and surface quality of the workpiece were also monitored to the veracity of the wear status of the wheel. The fundamental advantage of this method is the low cost of equipment compared with other techniques. As long as the processing speed of computers is improving, while the price of storage memory is keeping down, digital image processing will be more advantageous in the field of engineering. These widespread applications include quality control in manufacturing, tool monitoring in machining processes, surface roughness controlling, wheel wear monitoring in grinding, and many others [17]. Today, image processing is applied to examine the grinding wheel surface condition by some researchers. Su and Tarng [18] proposed a new method for measuring grinding wheel contours using machine vision. This method significantly simplifies grinding wheel wear measuring procedures compared with the traditional methods. The results show that this developed system achieves a repeatable accuracy of $\pm 3 \mu \mathrm{m}$ for the measurement of the grinding wheel contours. Feng and Chen [19] detected and identified the chip loading and cutting-edge wear of a grinding wheel by using the image processing toolbox of the MATLAB package. The different optical characters of the metal chips and the abrasive grains were analyzed to determine the threshold at the global level, and the wheel surface working status was monitored by this method. Luo and $\mathrm{Hu}$ [20] designed an online image measurement system for improving measurement precision. A new subpixel-level accuracy edge detection approach combined with Zernike moments operator and Sobel operator is proposed for locating the edge of the machined workpiece, which has advantages of fast processing speed and high edge locating accuracy. Arunachalam and Ramamoorthy [21] proposed a method to assess the working surface condition of the grinding wheel by the texture analysis method. Fourier power spectrum-based texture parameters are evaluated to identify the condition of the grinding wheel efficiently. Also, the results of image segmentation have a very significant impact on follow-up research about image recognition. The key of image segmentation is to determine the optimal threshold [22, 23]. The determination of the threshold is for a more accurate binary process. Binarization is the process that converts a multitone image into a bitonal image [24]. Binarization can serve as a noise removal process to increase document readability. The file size of binary images is often an order of magnitude smaller than the original gray or color images which makes them cheaper to store on disk. It is more fitting for industrialization.

In this paper, the relationships between the removal volume of the workpiece and the grinding force, the grinding temperature, and workpiece surface quality when grinding a workpiece in the material of Cr12 with an alumina wheel were studied. The status of the wearing wheel was determined based on the technology of image recognition. The rates of blockage area on the grinding wheel surface and the average ratio of the worn area [25] of a single abrasive on a worn wheel were calculated. Moreover, the relationship between the theoretical projection acreage of a single abrasive particle and the wear acreage obtained by image recognition was established.

\section{Monitor the Wear Process of the Wheel When Grinding the Workpiece of Cr12}

2.1. Experimental Setup. Dry surface grinding experiments were performed on a precision surface grinder (FSG-12/ 16AD, CHEVALIER). The workpiece made of Cr12 material was ground by a vitreous-bonded chromium corundum wheel. The size of the workpiece is $70 * 70 * 30 \mathrm{~mm}$. The details of the wheel are given in Table 1 . The grinding wheel needs to be sharpened before grinding. The workpieces have to be machined to ensure that the surface quality of the workpiece is consistent before each repeated grinding.

The scheme of the grinding experiment is shown in Figure 1. A dry grinding experiment is finished with different grinding parameters. The grinding temperature was monitored with thermocouples during the grinding process. The type of thermocouples is HVS-1000Z. The sandwichbedded thermocouples are the same as the literature [26]. The two-sample blocks clamp the thermocouple, and the thermocouple is slightly higher than the two-sample blocks. The tip part of the intermediate medium of the thermocouple is removed so that the two poles of the thermocouple at the temperature measuring end are overlapped together to form a temperature measurement loop. The sample block is fixed with a fixture. Ground the initial surface of the two blocks until they are spark out before the monitoring experiment. Then the grinding force was measured with a 
TABLE 1: Specification of grinding wheel.

\begin{tabular}{lccccc}
\hline Wheel type & Grain size & Abrasive structure & Abrasive volume ratio (\%) & Diameter $(\mathrm{mm})$ & Thickness $(\mathrm{mm})$ \\
\hline PSA46H10V & $46 \#$ & $10 \#$ & 44 & 355 & 50 \\
\hline
\end{tabular}

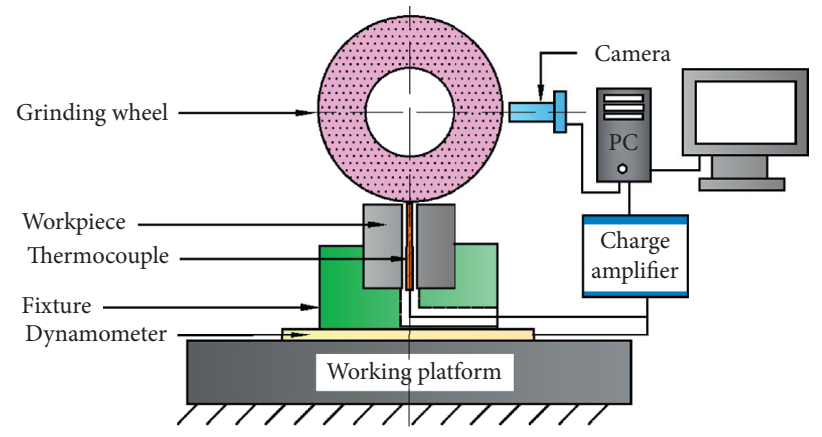

(a)

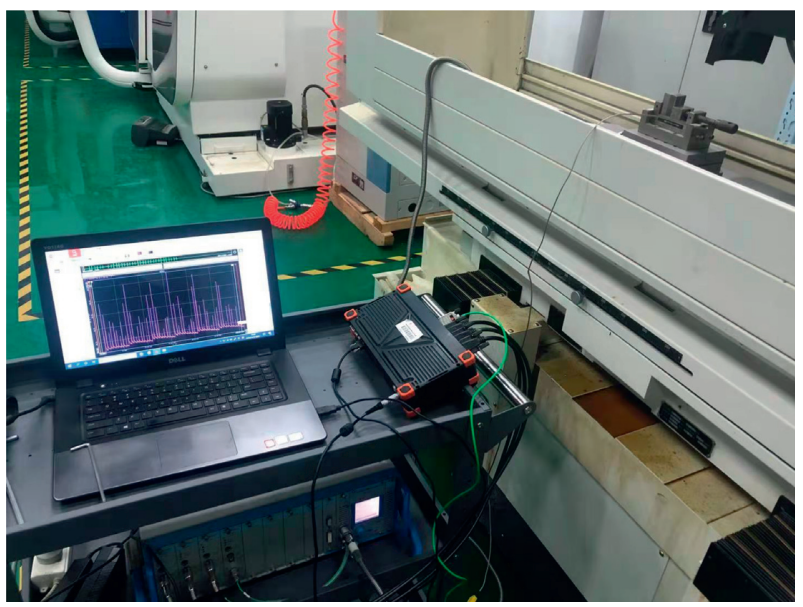

(b)

FIGURE 1: Schematic of grinding experiment: (a) experimental schematic and (b) experimental device.

dynamometer in model Kistler 9257B while grinding. The surface roughness of the workpiece was also measured by a portable roughness meter of model TIME 3220. After removing a reasonable volume of material, stop grinding and move a camera in the type of ZQ-603 nearby the grinding wheel to photograph the surface of the wheel on site without unloading it. Besides, a three-dimensional video microscope (KH-8700) was used to observe the surface morphology of the workpiece.

2.2. Research Plan. A tentative grinding experiment was carried out with different grinding parameters of the wheel speed, work speed, and depth of cut. The grinding force and temperature were measured regularly in this experiment. The influences of grinding parameters on grinding force and temperature were obtained. It is found that when $v_{s}=30 \mathrm{~m} / \mathrm{s}$, $a_{p}=25 \mu \mathrm{m}$, and $v_{w}=200 \mathrm{~mm} / \mathrm{s}$, it is in a stable grinding stage. Then the monitoring experiment was carried out with these parameters. The grinding wheel was gradually blunted with the increase of workpiece material removal, and then the grinding force and grinding temperature will vary. When the grinding wheel is blocked, the grinding force and grinding temperature will deviate from the values during stable grinding. At the same time, the surface of the wheel was recorded by the camera.

A region on the surface of the wheel was marked with a silicone impression material. The marked zone was regularly observed and was photographed during the process of wearing experiment. Then the software of MATLAB is used to process the image of the wheel. The sample pictures were grayed out; then the distribution of gray histogram was observed and analyzed. The gray thresholds of wear area and blockage area preliminaries were determined according to the distribution in different periods. The most suitable gray threshold was determined by changing the gray threshold, comparing the wear area and blockage area of the obtained binary image with the original image. Finally, the wear area rate and blockage area rate were determined by calculating the proportion of the binary image. $\mathrm{Pt}$ is the gray value as shown in Figure 2. $\mathrm{Thr}_{1}$ is the gray threshold of the wear area, and $\mathrm{Thr}_{2}$ is the gray threshold of the blocking area.

\section{Analysis of Experimental Results}

3.1. Determination of Grinding Parameters in Wearing Experimental. In Figure 3(a), it is shown that the increase of grinding wheel speed results in the increase of the grinding temperature generally but a significant decrease in normal grinding force and tangential grinding force. This is due to the increase of abrasive grains participating in cutting at the same time, and the grinding temperature naturally rises. The maximum undeformed chip thickness becomes smaller and the grinding force becomes smaller with the increase of effective abrasive grains participating in grinding. From Figure 3(b), it can be seen that the increase of grinding depth results in the increase of grinding temperature and grinding force, but the grinding temperature is stable finally. The reason is that, with the increase of grinding depth, the number of effective abrasive grains increases, which causes the grinding temperature to rise during the first period. In the stable area of effective abrasive grains, the grinding temperature is stable, but the maximum undeformed chip thickness will increase with the increase of grinding depth, and the grinding force will also increase. The results are roughly in agreement with the literature reported by Tan et al. [27]. 


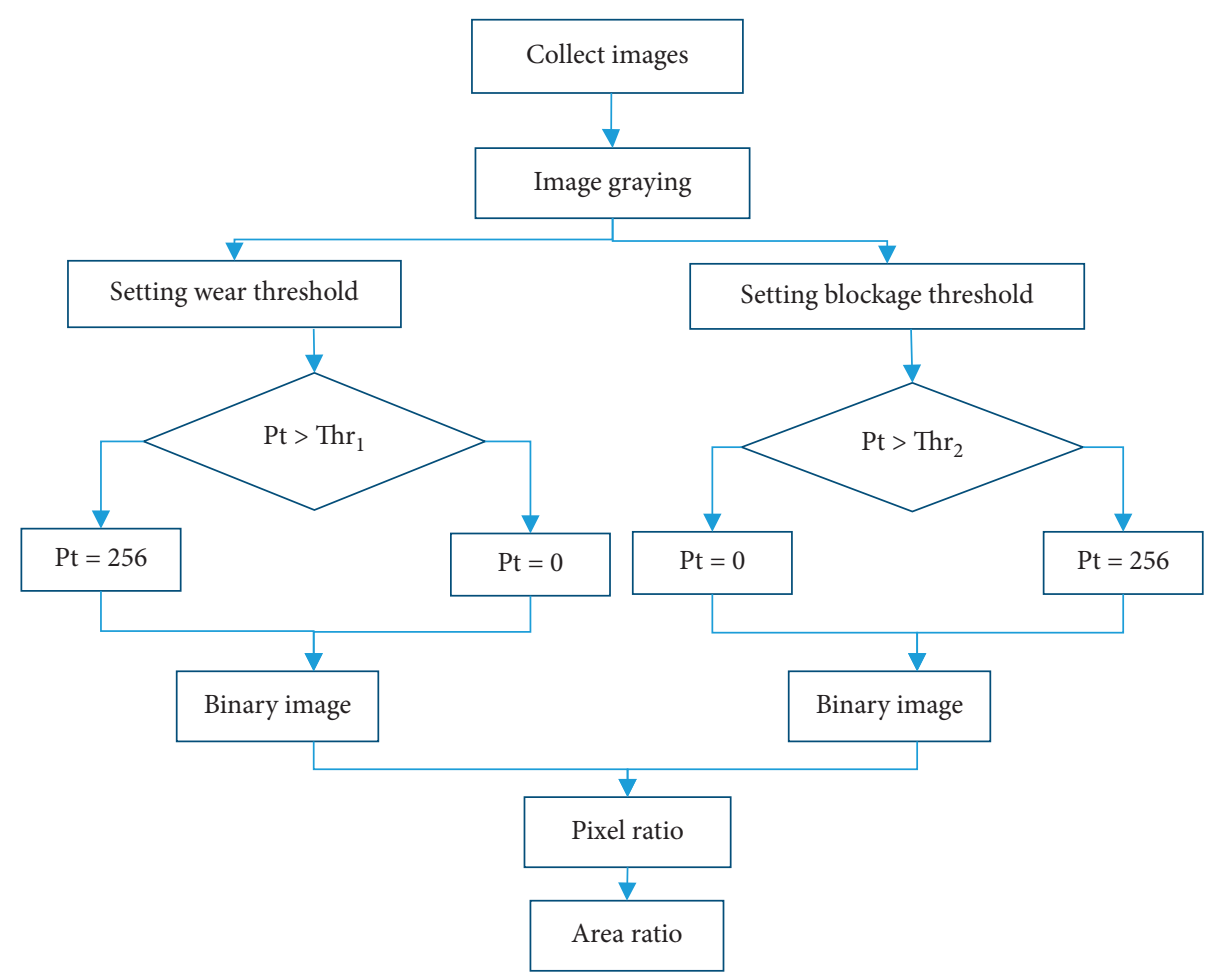

Figure 2: Image processing flowchart.

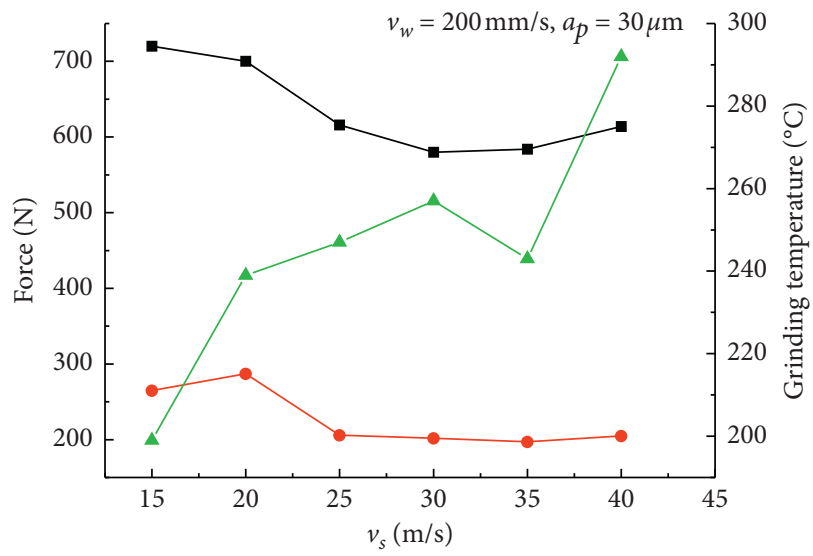

- Normal force

$\rightarrow$ Tangential force

$\neg$ Grinding temperature

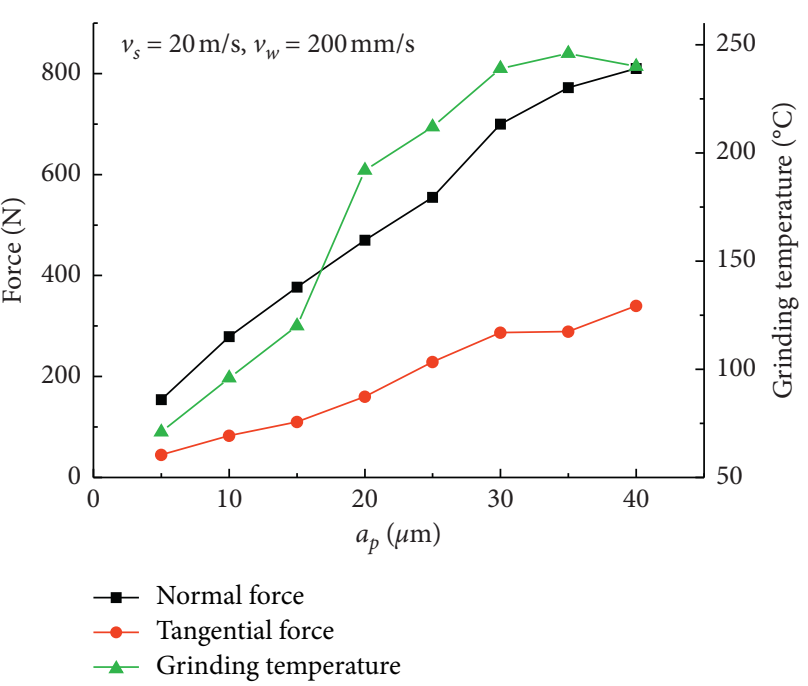

(a)

(b)

Figure 3: Continued. 


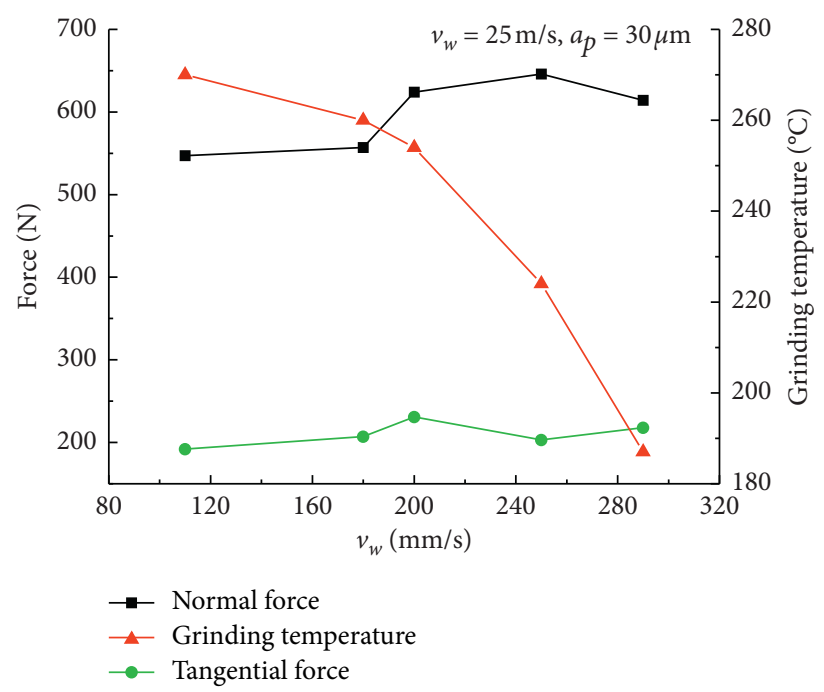

(c)

Figure 3: The influence of grinding parameters on grinding signals: (a) the influence of wheel speed, (b) the influence of grinding depth, and (c) the influence of feed speed.

The feature shown in Figure 3(c) is that the feed speed has a small influence on tangential grinding force but has a great influence on the normal grinding force. The reason is that the unit feed rate increases when the cutting speed of the grinding wheel increases, which makes the maximum undeformed chip thickness of a single abrasive grain increase. A large number of effective abrasive grains participating in grinding at the same time will inevitably increase the normal grinding force. However, the sliding friction force increases with the increase of feed rate, which increases the normal grinding force. The grinding contact time becomes shorter resulting in shorter heat generation time. Therefore, the grinding temperature shows a downward trend with the increase of workpiece feeding speed. Based on the above analysis, the grinding parameters for the monitoring experiment are determined as $v_{s}=30 \mathrm{~m} / \mathrm{s}, a_{p}=25 \mu \mathrm{m}$, and $v_{w}=200 \mathrm{~mm} / \mathrm{s}$ to avoid excessive grinding temperature and maintain low grinding force and certain grinding efficiency.

3.2. Monitoring the Wear Process of the Grinding Wheel. With the increase of the material removal, the abrasive grains will wear and fall off and the grinding wheel also may be blocked. Then the grinding performance of the wheel will degrade, which will vary the grinding temperature and grinding force and even decline the surface quality of the workpiece. Therefore, the grinding temperature, the grinding force, and the surface quality of the workpiece can be used as indexes to evaluate the wear of the wheel. The tracking experiment for wear was carried out with the grinding parameters, where $v_{s}=30 \mathrm{~m} / \mathrm{s}, a_{p}=25 \mu \mathrm{m}$, and $v_{w}=200 \mathrm{~mm} / \mathrm{s}$. By monitoring the grinding states corresponding to the removal amount of workpiece materials, the index of the blunting of the grinding wheel can easily be identified.
3.2.1. Effect of Material Removal Volume on Grinding Temperature and Grinding Force. The influence of grinding depth on grinding temperature is shown in Figure 4(a). It can be seen that the grinding temperature gradually increases with the increase of the cumulative removal volume of materials as consistent as that which has been studied in early literature [28]. The grinding temperature increases proportionally with $V^{\prime}$ in the range of $V^{\prime}=0 \sim 60 \mathrm{~mm}^{3} / \mathrm{mm}$, and the growth rate is $0.67^{\circ} \mathrm{C} /$ $\left(\mathrm{mm}^{3} / \mathrm{mm}\right)$. When $V^{\prime}=60 \sim 210 \mathrm{~mm}^{3} / \mathrm{mm}$, the grinding temperature increases slowly, and the growth rate is $0.23^{\circ} \mathrm{C} /\left(\mathrm{mm}^{3} / \mathrm{mm}\right)$. When $V^{\prime}=210 \sim 290 \mathrm{~mm}^{3} / \mathrm{mm}$, the change of grinding temperature is accelerated, and the growth rate is $0.5^{\circ} \mathrm{C} /\left(\mathrm{mm}^{3} / \mathrm{mm}\right)$. The increase of temperature is mainly due to a fracture that accounted for a major part of the wheel wear during the initial wear stage, and attrition wear is the dominant wear mechanism occurring during the normal wear stage. Then the fracture of whole grains from the wheel is the severe wear stage. According to the previous analysis and data, it can be considered that the grinding wheel is seriously worn when $V^{\prime}=210 \mathrm{~mm}^{3} / \mathrm{mm}$.

It can be seen from Figure 4(b) that the tangential grinding force increases slightly at the initial stage with the increase of material removal volume and then becomes stable with hardly any change. The normal grinding force increases with increasing grinding time. This is because, in the early stage, the effective abrasive grains of the grinding wheel increased rapidly, and the tangential force and the normal force on the workpiece increase rapidly. In the middle and later stages, the abrasive wear area of the grinding wheel and the normal grinding force increase. The grinding force ratio decreases and then increases from 2.68 to 3.5. The grinding force ratio is relatively high at the initial stage of grinding, which may be due to the initial wear. 


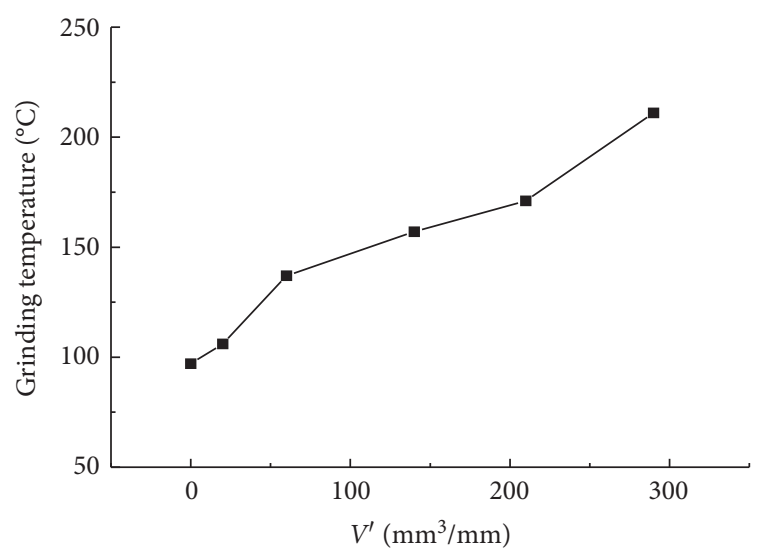

(a)

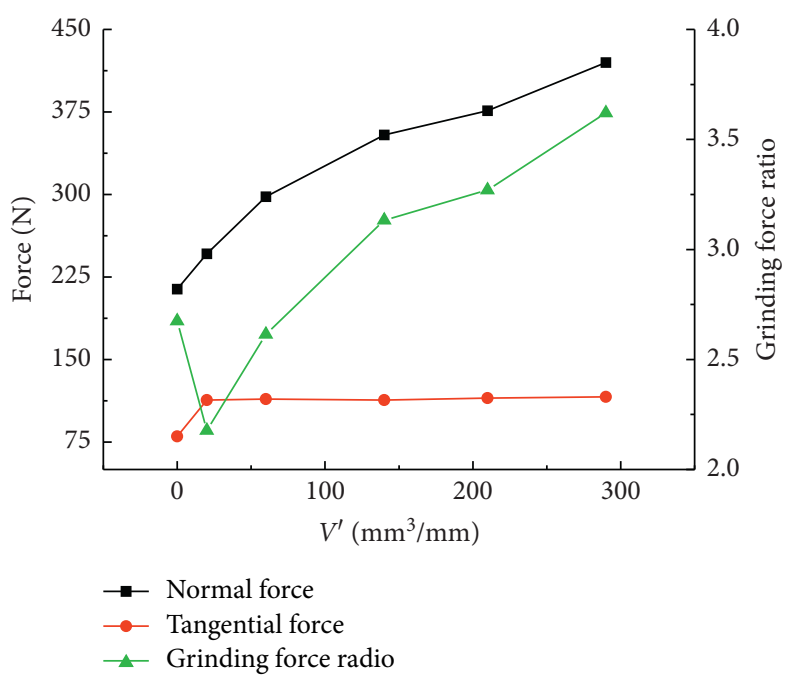

(b)

Figure 4: Effects of material removal per unit width of wheel on the grinding temperature and the grinding force. (a) The grinding temperature and (b) the grinding force and the grinding force ratio.

3.2.2. Effect of Material Removal Volume on the Surface Quality of the Workpiece. The ground surface of the workpiece usually shows different colors with different grinding temperature due to the change of material microstructure [29]. In this work, the surface morphology of the ground workpiece in Figure 5 shows that the color of the workpiece is generally iron cyan when the cumulative material removal volume per unit width increases from $V^{\prime}=20 \mathrm{~mm}^{3} / \mathrm{mm}$ to $V^{\prime}=140 \mathrm{~mm}^{3} / \mathrm{mm}$. The surface of the workpiece maintains the original color. However, it begins to turn into dry yellow when $V^{\prime}$ reached $210 \mathrm{~mm}^{3} / \mathrm{mm}$, as shown in Figure 5(d). It is mainly due to the wheel gradually dulling, and some of the abrasive particles fall off. Then the rising of the grinding temperature leads to oxidation of the workpiece surface. From Figure 5(e), it can be found that the surface of the workpiece is not only oxidized but also burned when $V^{\prime}=290 \mathrm{~mm}^{3} / \mathrm{mm}$. It can be inferred that the wheel has deteriorated, and it is not suitable for further working.

As shown in Figure 6, with the increase of material removal volume, the surface hardness of the workpiece first increases and then decreases. The main reason is that, in the initial stage of the grinding, the grinding force is dominant, and the work hardening is significant. In the later stage of grinding, the grinding wheel wears gradually, and the grinding temperature slightly increases. With a large number of abrasive particles involved in cutting, the metal removal rate increases, and the surface temperature of the workpiece rises; the hardness of Cr12 decreases with the rise of tempering temperature.

In summary, when the cumulative volume of material removal reaches $210 \mathrm{~mm}^{3} / \mathrm{mm}$, the grinding force, grinding temperature, and surface quality of the workpiece vary significantly. Continuous grinding might cause obvious burns and affect the quality of the machined workpiece.
3.3. Effect of Material Removal Volume on the Image of the Wheel Surface. Determining the wear status of the grinding wheel is usually based on the routine experience method. Some researchers give comprehensive evaluations of grinding wheel wear by measuring the grinding temperature, grinding force, and acoustic emission detection. A better way is expected to explore the proportion of the wear area of a single abrasive and the ratio of the wear acreage on the surface of a grinding wheel to evaluate the wear status.

3.3.1. Wear Threshold. The surface of the grinding wheel was photographed at different stages while grinding. The ratio of pixels with different gray values is expressed in the histogram. The results are presented in Figure 7 . The distribution of these pixels showed normal distribution at the beginning. They present the trend to move from the middle to both sides with the increase of material removal of cumulative volume. When the grinding wheel is in a state of obvious wear, there is a distribution of the dramatic increase in the number of pixels to near 256. The reason is likely that the cutting performance of abrasives is perfect in the early stage, with only a handful of abrasive damage. The tendency of pixels moving to both sides of the coordinate is not clear. As the grinding continues, the wear increases. The color of chromium corundum alumina grains will turn from red to white after fracturing. On the other hand, fracture debris blocking the pores results in a shadow area, which appears to be black. So, statistical histograms of pixels are needed to move forward both ends. Then it presents a bimodal distribution. It is inferred that the wearing area threshold of gray level is $215 \sim 225$. After processing the image, the value of the threshold is determined to be 220 .

3.3.2. Wear Area Ratio of Single Abrasive. Based on the summary in Section 3.2, the grinding wheel has been worn when $V^{\prime}$ reaches $210 \mathrm{~mm}^{3} / \mathrm{mm}$. The photos of the abrasive 


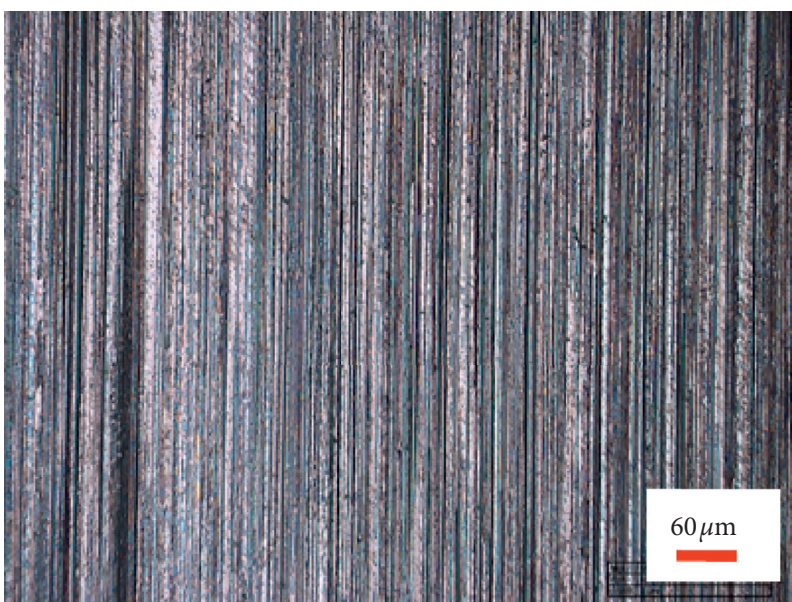

(a)

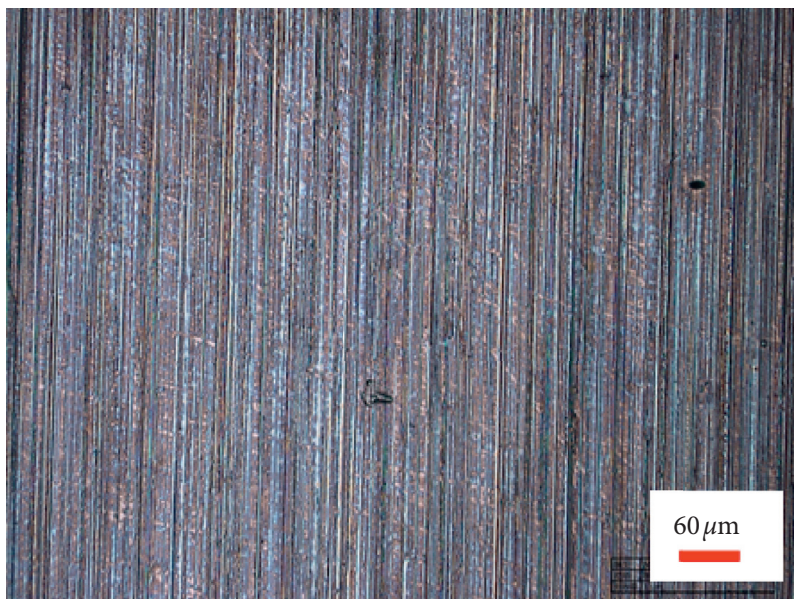

(c)

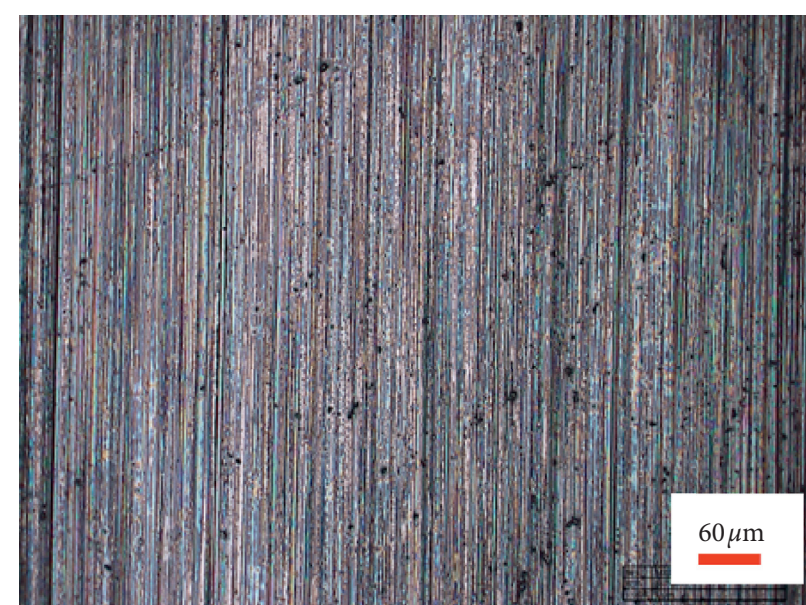

(b)

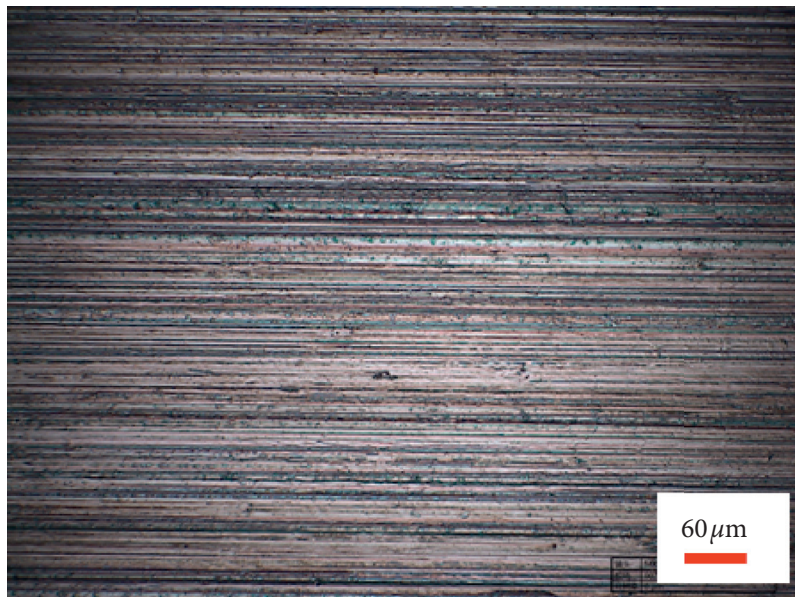

(d)

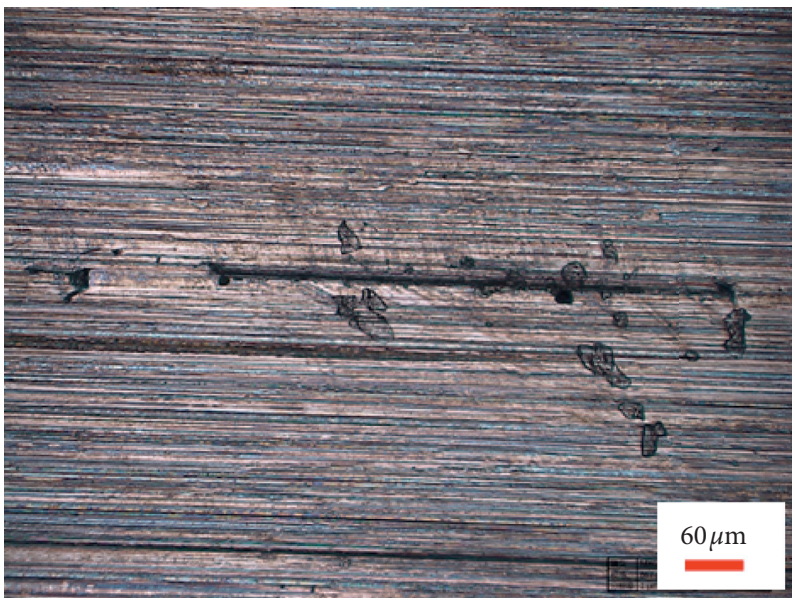

(e)

FIGURE 5: The surface morphology with different cumulative material removal. (a) $V^{\prime}=20 \mathrm{~mm}^{3} / \mathrm{mm}$, (b) $V^{\prime}=60 \mathrm{~mm}^{3} / \mathrm{mm}^{3}$, (c) $V^{\prime}=140 \mathrm{~mm}^{3} / \mathrm{mm}$, (d) $V^{\prime}=210 \mathrm{~mm}^{3} / \mathrm{mm}$, and (e) $V^{\prime}=290 \mathrm{~mm}^{3} / \mathrm{mm}$.

grains on the surface of the grinding wheel were drawn from the map of the wheel, as shown in Figure 8(a). Assuming that particle size is $400 \mu \mathrm{m}$, the maximum cross-sectional area is $0.1256 \mathrm{~mm}^{2}$. There is a need to ensure that the abrasive particles keep sufficient holding force and ensure that $3 / 4$ of the abrasive particles are embedded in the matrix; the maximum projection area on the surface of the wheel is $0.0314 \mathrm{~mm}^{2}$. There are not many grains that could be ground. Then the projection area of wear particles between $0.020 \mathrm{~mm}^{2}$ and $0.030 \mathrm{~mm}^{2}$ is derived. 


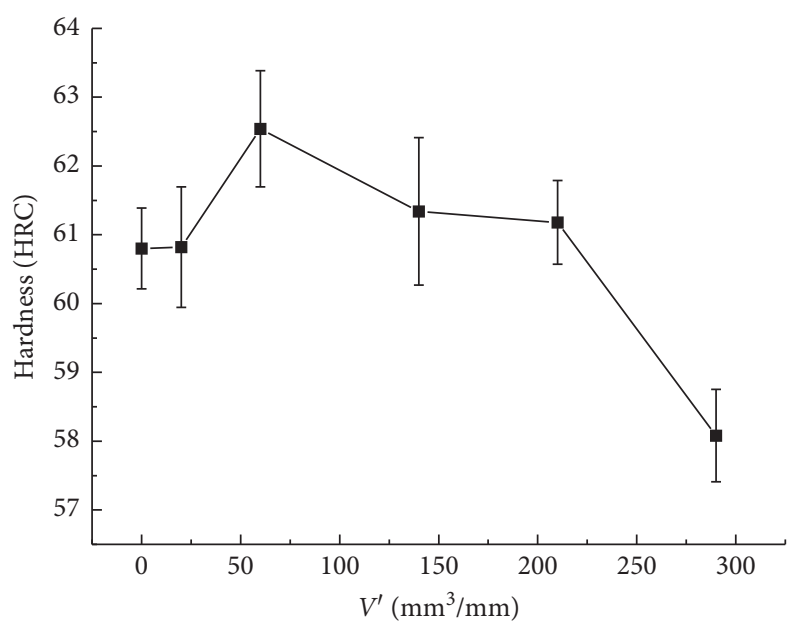

FIGURE 6: Hardness of the workpiece varies with the cumulative removal.

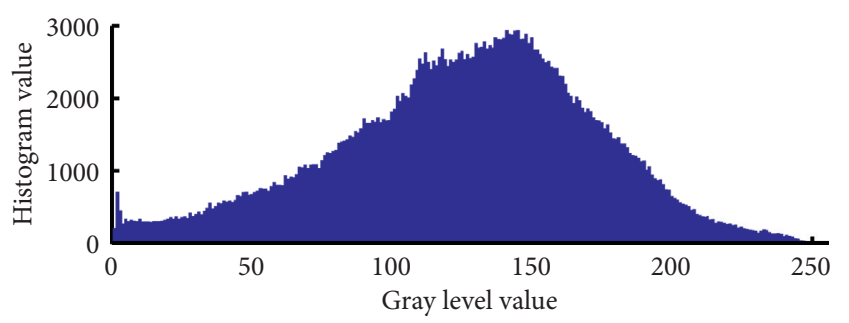

(a)

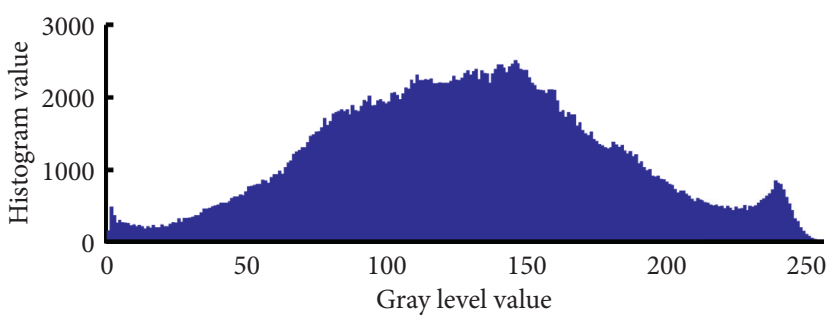

(b)

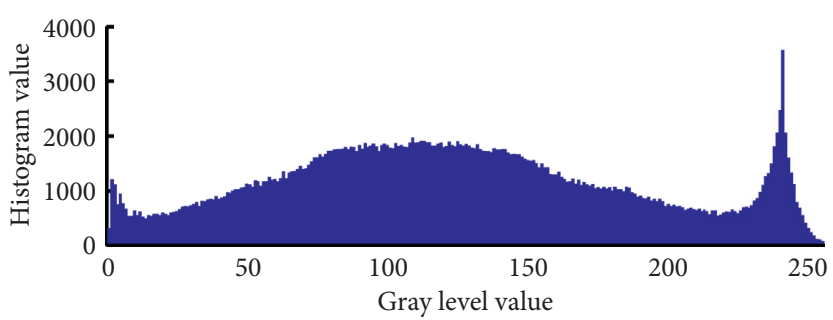

(c)

Figure 7: Effect of cumulative material removal on pixels. (a) $V^{\prime}=20 \mathrm{~mm}^{3} / \mathrm{mm}$, (b) $V^{\prime}=140 \mathrm{~mm}^{3} / \mathrm{mm}$, and (c) $V^{\prime}=290 \mathrm{~mm}^{3} / \mathrm{mm}$.
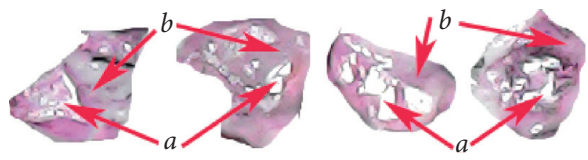

(a)

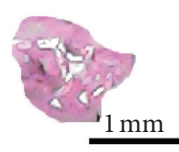

$1 \mathrm{~mm}$

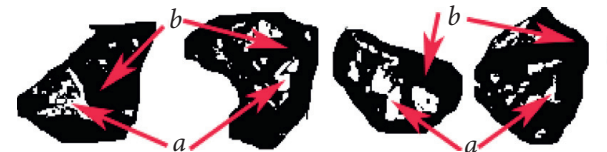

(b)

Figure 8: The binarized image of abrasive particles. (a) The original image of wear particles collected and (b) the image after binarizing.

Liu and $\mathrm{Ou}$ [30] concluded that the worn grain is usually shown as high brightness. In this paper, the appearance of wear abrasive in the image is in line with it. Figure $8(\mathrm{~b})$ shows single abrasive images drawn from the map of the grinding wheel. The highlight region is expressed as " $a$ " in Figure 8(a). The nonwear part of the abrasive is pink as the region of " $b$." A processed binary graph using a self-defining threshold is shown in Figure 8(b). The wear part calculating the proportion of the worn area is pure white as the region " $a$ " in Figure 8(b). The nonwear part is pure black as the region " $b$ " in Figure 8(b). The whole abrasive consists of two parts " $a$ " and " $b$." Therefore, the proportion of the wear part area $r$ can be expressed as

$$
r=\frac{a}{(a+b)} \text {. }
$$

The most common method of image segmentation is the threshold technique. It relies on a clip-level or a threshold value to turn a grayscale image into a binary image. The key to this method is the value of the threshold. 
The segmentation area is determined to be $0.001 \mathrm{~mm}^{2}$ for calculation, taking into account individual differences of particle embedding. The results are shown in Figure 9.

Figure 9 shows that the histogram under different projection areas is normal distribution, which may be due to the different embedding ways of wear particles, resulting in the alienation of the projection area. However, the ratio of the wear area increases first and then decreases. The effect of wear which is more critical in the early stages of the grinding process might be due to the large projection area and high cutting edge. While the wear particles may fall off [31, 32] when part of the wear is more critical in the following stage, the number of worn particles still embedded on the grinding wheel will decrease. The proportion of the wear part area $r$ is then calculated by averaging the ratio wear area of each abrasive particle. Then the average ratio of the wear area of single abrasive grain is $8.77 \%$.

3.3.3. The Ratio of Wear Area on the Wheel Surface. Perform processing of the binary image of the wheel surface based on the threshold derived above. The pixel whose gray value is greater than 220 is set as pure white; otherwise it is set as black color. The result is shown in Figure 10. The area of the highlighted white part on the graph is defined as $s_{1}$ and the area of the whole picture is defined as $s_{2}$. The ratio of the wear area is expressed as $s$. The acreage in pure white color is calculated by statistics of the number of pixels with the MATLAB software. So the ratio of the wear area on the picture is calibrated as $s$.

Calculate the proportion of wear area in different grinding stages. Counting the blockage acreage of the wheel using the same way, the results are achieved and shown in Figure 11. It can be clear that the wear area gradually increases with the increase of the material removal volume. Because the speed of initial wear is fast at the preliminary stage of grinding, then the wear area is increased greatly. When the material removal volume exceeds $210 \mathrm{~mm}^{3} / \mathrm{mm}$, the most likely cause of the wear trend slowing down is the serious wear of the grinding wheel and the appearance of new abrasive particles, resulting in a slight decrease in the wear proportion and a slowing downtrend in wear area ratio.

The trend of wear keeps the same trend with the grinding force, grinding temperature, and surface quality until the ratio of wear area reaches $9.5 \%$ and the blocking area rate reaches $13.4 \%$. Then the grinding wheel has already seriously worn at this time. The value of the ratio can apply for judging the wear of alumina grinding wheel when grinding Cr12. Considering the variation of the grinding force, the grinding temperature, and the surface quality, it can be deduced that the wear rate of the grinding wheel is $9.5 \%$.

To further explain the variation trend of wear, based on the experimental data in Figure 11, the regression model is set up, respectively. When the material removal volume per unit length is $0-300 \mathrm{~mm}^{3} / \mathrm{mm}$, it can be found that the material removal volume has a good linear relationship with the wear area rate and the loading area rate. The linear regressive equations and coefficient of correlation, respectively, are

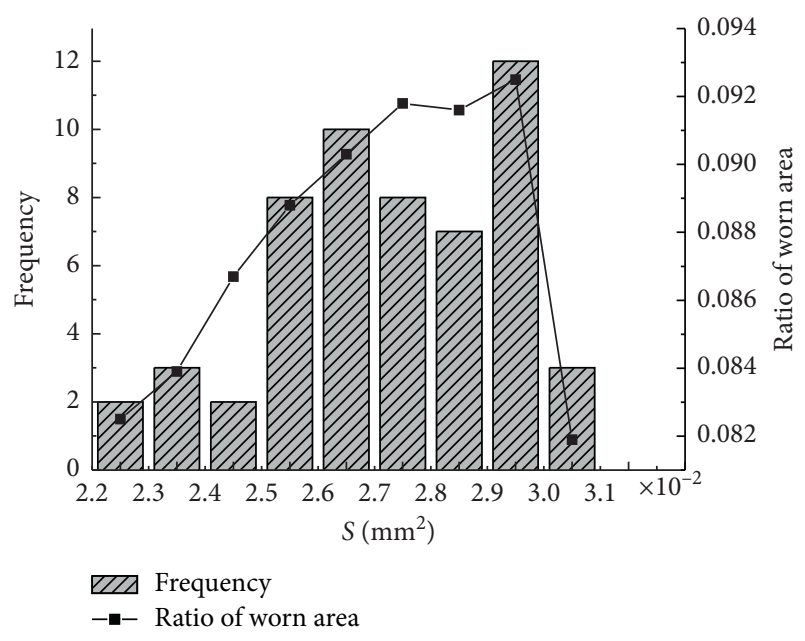

FIGURE 9: The histogram of the projected area of worn particles.

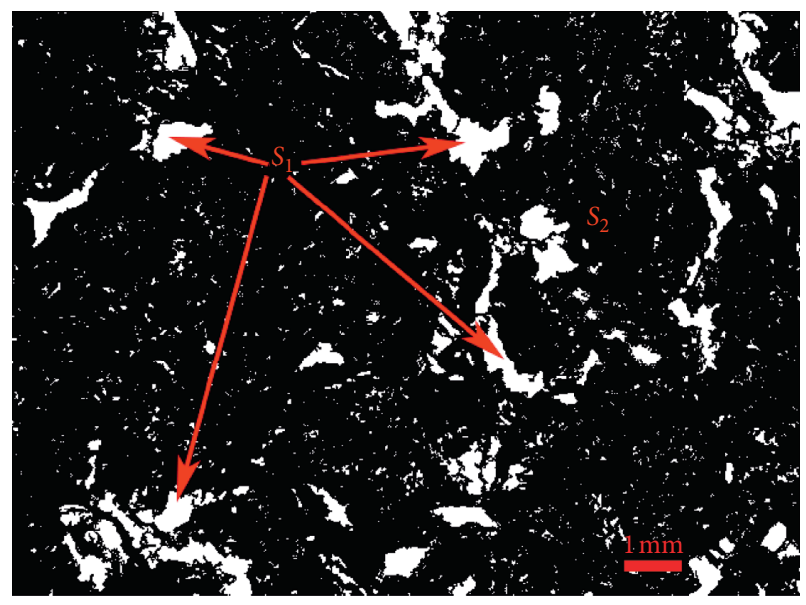

FIGURE 10: Binary diagram of the wheel surface.

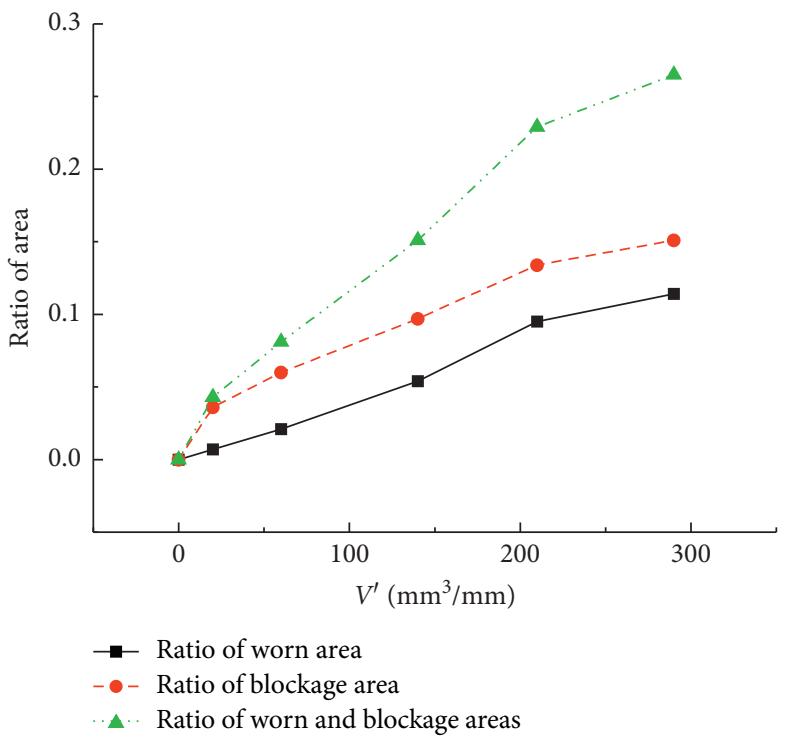

FIgURE 11: The effect of material removal volume on the ratio of wear and blockage. 


$$
\begin{array}{ll}
y_{1}=0.0004 x-0.0011, & \left(R^{2}=0.9889\right) \\
y_{2}=0.0005 x+0.0201, & \left(R^{2}=0.9493\right) \\
y_{3}=0.0009 x+0.019, & \left(R^{2}=0.9792\right)
\end{array}
$$

where $y_{1}$ is the ratio of the wear area, $y_{2}$ is the ratio of blockage area, and $y_{3}$ is the proportion of wear and blockage area of the total surface of the wheel. With the increase of material removal volume, the wear area and blockage area of the grinding wheel increase correspondingly. It means that the surface of the grinding wheel is modified. Thus, these equations are of positive significance for future research on judging the degree of blockage and wearing of the grinding wheel.

\section{Conclusion}

By monitoring the surface of the grinding wheel in different periods of grinding, the following conclusions are drawn:

(1) By tracing the surface of the grinding wheel and comparing the gray value distribution of pixels before and after grinding, a fresh wave peak appears on the right side of the original wave due to the wear of grain. The value of the gray level of 220 between the two waves can be taken as the threshold for dividing the wear area.

(2) The single-abrasive particles on the surface of the grinding wheel are photographed after the grinding wheel was worn, and the average calculated wear area ratio of a single particle is $8.77 \%$. Compared with the average wear area ratio of $9.5 \%$ of the tracking region, the deviation is $7.68 \%$.

(3) The ratio of the wear area increases with the increase of removal volume of material. When material removal volume reaches $210 \mathrm{~mm}^{3} / \mathrm{mm}$, the wear area ratio is $9.5 \%$, and the surface quality of the workpiece deteriorates.

The method of determining the ratio of the wear area can assist in judging the status of the wheel. By controlling the wear of the grinding wheel, the defects on the surface of the workpiece caused by the wear of the wheel can probably be avoided. This method can monitor the wear of the grinding wheel in situ without removing the grinding wheel and can also be applied to other grinding wheels in forthcoming work of intelligent manufacturing.

\section{Nomenclature}

Pt: Gray value

$\mathrm{Thr}_{1}$ : Gray threshold of wear area

$\mathrm{Thr}_{2}$ : Gray threshold of blockage area

$a_{p}: \quad$ Grinding depth $(\mu \mathrm{m})$

$v_{s}$ : Grinding wheel speed $(\mathrm{m} / \mathrm{s})$

$v_{w}: \quad$ Feed speed $(\mathrm{mm} / \mathrm{s})$

$V^{\prime}$ : Accumulated material removal per unit width $\left(\mathrm{mm}^{3} / \mathrm{mm}\right)$

$a$ : Wear acreage of single abrasive $\left(\mathrm{mm}^{2}\right)$ $b$ : Nonwear acreage of single abrasive $\left(\mathrm{mm}^{2}\right)$

$r$ : Wear area ratio of single abrasive

$s_{1}$ : The acreage of the wear region $\left(\mathrm{mm}^{2}\right)$

$s_{2}$ : The acreage of the whole picture $\left(\mathrm{mm}^{2}\right)$

$s$ : The ratio of wear acreage on the surface of the wheel

$S$ : $\quad$ Projected area of abrasive particles.

\section{Data Availability}

No data were used to support this study.

\section{Conflicts of Interest}

The authors declare that there are no conflicts of interest.

\section{Acknowledgments}

This work was supported by the National Natural Science Foundation of China (no. 51375180).

\section{References}

[1] Z. Yang and Z. Yu, "Grinding wheel wear monitoring based on wavelet analysis and support vector machine," The International Journal of Advanced Manufacturing Technology, vol. 62, no. 1-4, pp. 107-121, 2012.

[2] B. Karpuschewski, M. Wehmeier, and I. Inasaki, "Grinding monitoring system based on power and acoustic emission sensors," CIRP Annals, vol. 49, no. 1, pp. 235-240, 2000.

[3] X. Wu, J. Shen, F. Jiang, H. Wu, and L. Li, "Study on the oxidation of WC-Co cemented carbide under different conditions," International Journal of Refractory Metals and Hard Materials, vol. 94, pp. 1-8, 2021.

[4] F. R. L. Dotto, P. R. Aguiar, F. A. Alexandre et al., "Acoustic image-based damage identification of oxide aluminum grinding wheel during the dressing operation," Procedia CIRP, vol. 79, pp. 298-302, 2019.

[5] X. Chen, W. B. Rowe, D. R. Allanson, and B. Mills, "A grinding power model for selection of dressing and grinding conditions," Journal of Manufacturing Science and Engineering, vol. 121, no. 4, pp. 632-637, 1999.

[6] C. W. Lee, T. Choi, and Y. C. Shin, "Intelligent model-based optimization of the surface grinding process for heat-treated 4140 steel alloys with aluminum oxide grinding wheels," Journal of Manufacturing Science and Engineering, vol. 125, no. 1, pp. 65-76, 2003.

[7] S. J. Deutsch and S. M. Wu, "Analysis of mechanical wear during grinding by empirical-stochastic models," Wear, vol. 29, no. 2, pp. 247-257, 1974.

[8] Z. Shi and S. Malkin, "Wear of electroplated CBN grinding wheels," Journal of Manufacturing Science and Engineering, vol. 128, no. 1, pp. 110-118, 2006.

[9] D. V. Ardashev and A. A. Dyakonov, "Mathematical model of the grinding force with account for blunting of abrasive grains of the grinding wheel," Journal of Manufacturing Science and Engineering, vol. 139, no. 12, 2017.

[10] G. X. Yin, T. Nisal, I. D. Marinescu, and N. T. Bugtai, "Monitoring the parameter effects of surface grinding process using temperature, acoustic emission and force measurement," in Proceedings of the ASME 2014 International Manufacturing Science and Engineering Conference, Detroit, MI, USA, June 2014. 
[11] A. G. Skhirtladze and V. A. Skryabin, "Technology of repairing abrasive tools," Russian Metallurgy (Metally), vol. 2017, no. 13, pp. 1176-1181, 2017.

[12] A. Lefebvre, P. Vieville, P. Lipinski, and C. Lescalier, "Numerical analysis of grinding temperature measurement by the foil/workpiece thermocouple method," International Journal of Machine Tools and Manufacture, vol. 46, pp. 1716-1726, 2005.

[13] E. Brinksmeier, J. Eckebrecht, and A. Wilkens, "Wheel based temperature measurement in grinding," Advanced Materials Research, vol. 325, pp. 3-11, 2011.

[14] B. K. Li, C. W. Dai, W. F. Ding et al., "Prediction on grinding force during grinding powder metallurgy nickel-based superalloy FGH96 with electroplated CBN abrasive wheel," Chinese Journal of Aeronautics, vol. 1539, pp. 1-10, 2020.

[15] A. Thanedar, G. G. Dongre, R. Singh, and S. S. Joshi, "Surface integrity investigation including grinding burns using barkhausen noise (BNA)," Journal of Manufacturing Processes, vol. 30, pp. 226-240, 2017.

[16] B. Azarhoushang, A. Daneshi, and D. H. Lee, "Evaluation of thermal damages and residual stresses in dry grinding by structured wheels," Journal of Cleaner Production, vol. 142, pp. 1922-1930, 2017.

[17] A. Hamed, S. M. Rezaei, and A. A. D. Sarhan, "Grinding wheel loading evaluation using digital image processing," Journal of Manufacturing Science and Engineering, vol. 136, pp. 1-10, 2014.

[18] J. C. Su and Y. S. Tarng, "Measuring wear of the grinding wheel using machine vision," The International Journal of Advanced Manufacturing Technology, vol. 31, no. 1-2, pp. 50-60, 2006.

[19] Z. Feng and X. Chen, "Image processing of the grinding wheel surface," The International Journal of Advanced Manufacturing Technology, vol. 32, no. 5-6, pp. 452-458, 2007.

[20] Y. M. Luo and D. J. Hu, "Real-time measurement and compensation for wheel wear in curve grinding based on image processing method," Key Engineering Materials, vol. 359-360, pp. 479-483, 2008.

[21] N. Arunachalam and B. Ramamoorthy, "Fourier Transform based texture measures for grinding wheel condition monitoring using machine vision," International Journal of Manufacturing Technology and Management, vol. 21, no. 1-2, pp. 112-121, 2010.

[22] S. B. Song, J. F. Liu, H. Y. Ni, X. L. Cao, H. Pu, and B. X. Huang, "A new automatic thresholding algorithm for unimodal gray-level distribution images by using the gray gradient information," Journal of Petroleum Science and Engineering, vol. 190, pp. 1-7, 2020.

[23] V. Gopan and K. L. D. Wins, "Quantitative analysis of grinding wheel loading using image processing," Procedia Technology, vol. 25, pp. 885-891, 2016.

[24] C. Tensmeyer and T. Martinez, "Historical document image binarization: a review," SN Computer Science, vol. 173, no. 1, pp. 1-26, 2020.

[25] T. Y. Yu, A. F. Bastawros, and A. Chandra, "Experimental characterization of electroplated CBN grinding wheel wear: topology evolution and interfacial toughness," in Proceedings of the ASME 2014 International Manufacturing Science and Engineering Conference, Detroit, MI, USA, June 2014.

[26] F. Y. You, J. Y. Shen, and X. P. Xu, "A method for calculating the maximal temperature of single grain though analyzing the grinding temperature signal," Key Engineering Materials, vol. 416, pp. 98-102, 2009.
[27] Y. F. Tan, P. Martin, C. Lescalier, O. Bomont, R. Bigot, and J. Arzur, "Study on the ground surface quality of $\mathrm{Cr}_{2} \mathrm{O}_{3}$ coatings," Journal of Materials Processing Technology, vol. 129, no. 1-3, pp. 441-445, 2002.

[28] J. Chen, H. Huang, and X. Xu, "An experimental study on the grinding of alumina with a monolayer brazed diamond wheel," The International Journal of Advanced Manufacturing Technology, vol. 41, no. 1-2, pp. 16-23, 2009.

[29] X. P. Xu, Y. Q. Yu, and H. J. Xu, "Effect of grinding temperatures on the surface integrity of a nickel-based superalloy," Journal of Materials Processing Technology, vol. 129, no. 1-3, pp. 359-363, 2002.

[30] C. S. Liu and Y. J. Ou, "Grinding wheel loading evaluation by using acoustic emission signals and digital image processing," Sensors, vol. 20, no. 15, pp. 1-13, 2020.

[31] H. Karasawa, T. Yoshida, R. Fukui, T. Kizaki, K. Fujii, and S. i. Warisawa, "Analysis of chip shape distribution using image processing technology to estimate wearing condition of gear grinding wheel," Procedia CIRP, vol. 81, pp. 381-386, 2019.

[32] A. Sakaguchi, T. Kawashita, and S. Matsuo, "Development of three-dimensional measurement system of a grinding wheel surface with image processing," Advanced Materials Research, vol. 325, pp. 294-299, 2011. 